\title{
Bronchospasm Diagnosis in Motorcycle Taxi Drivers Exposed to Automotive Pollutants in Porto-Novo
}

\author{
Folly Messan $^{1 \#}$, Mohamed Lawani², Barnabé Akplogan², Pierre Dansou ${ }^{1}$, \\ Daouda Mama ${ }^{3}$, Rodrigue Hounkponou ${ }^{1}$, Rodrigue A. Dagnitché ${ }^{1}$ \\ ${ }^{1}$ Laboratory of PSA and Motricity, National Institute of Youth, \\ Physical Education and Sport (INJEPS), University of Abomey-Calavi, Cotonou, Republic of Benin \\ ${ }^{2}$ Laboratory of Biomechanics and Performance (LABIOP), National Institute of Youth, \\ Physical Education and Sport (INJEPS), University of Abomey-Calavi, Cotonou, Republic of Benin \\ ${ }^{3}$ Laboratory of Applied Hydrology, Faculty of Sciences and Technics, \\ University of Abomey-Calavi, Cotonou, Republic of Benin \\ Email: ${ }^{\#}$ messfly@yahoo.fr
}

Received October 26, 2012; revised November 28, 2012; accepted December 5, 2012

\begin{abstract}
Background: In African cities, chronic exposure to pollutants is the most common public health problem faced daily by motorcycle taxi drivers. In Benin, studies conducted on motorcycle drivers, have shown the presence of nitrogen oxides, carbon monoxide, sulfur dioxide, volatile organic compounds and particulate matter in ambient air, which may affect lung function. Aims: This study aims to diagnose potential respiratory problems among 48 motorcycle taxi drivers (47.02 \pm 8.75 years) compared to a control group made up of 52 people ( $46.38 \pm 8.81$ years) in Porto-Novo, Benin. Methods: A questionnaire, two exploration pulmonary function tests and two 6-minute walk tests were used to identify symptoms and changes in respiratory variables that reveal the existence of bronchospasm. Results: The frequency of respiratory symptoms noted among motorcycle taxi drivers is higher than that recorded among members of the control group. We observed that motorcycle drivers at rest and after physical effort have significantly lower respiratory variables $\left(\mathrm{FVC}, \mathrm{FEV} 1, \mathrm{PEF}, \mathrm{FEF}_{25-75}, \mathrm{FEF}_{50}\right.$ and $\left.\mathrm{FEF}_{25}\right)(p<0.05)$ than those recoded in control group. Conclusion: It can therefore be concluded that, because of the relatively long duration of exposure among motorcycle taxi drivers, the inhalation of automobile pollutants, may cause respiratory problems in this population.
\end{abstract}

Keywords: Automobile Pollution; Asthma; Bronchospasm; Urban Pollution; Motorcycle-Taxi Drivers; Benin

\section{Introduction}

The socioeconomic status of West African countries has not improved despite the implementation of the Millennium Development Objectives in 2000, which aim to reduce extreme poverty and hunger, improve health and ensure environmental sustainability by 2015 . With less than five years left to meet these goals, it is clear that problems still remain, including relatively low rates of children enrolled in school, high poverty rates and high levels of environmental pollution generated by urban transport in African capital cities. Indeed, urban population growth, migration of young people from villages to cities, massive layoffs of civil servants resulting from the structural adjustment programs imposed by the Bretton Woods Institutions in the 1980s and the devaluation of the currency of the African Financial Community (CFA) in 1994, have resulted in a high rate of unemployment in West African countries in general and in Benin in par-

\footnotetext{
*The authors declare no conflict of interest.

\#Corresponding author.
}

ticular. This crisis is most acutely felt in Benin's major cities, such as Cotonou and Porto-Novo where low incomes and the lack of transportation policy governing urban public transportation have given rise to informal transportation activity led by motorcycle taxi drivers. These motorcycles imported from Europe are locally called "Zémidjan" and $95 \%$ of them have used engines that emit thick black smoke into the atmosphere, particularly at intersections during peak traffic hours. The fumes are generated by incomplete combustion of hydrocarbons and other particles due to mechanical failures of the automobiles poorly maintained motors and the poor quality of fuel illegally imported from neighboring, Nigeria. These motorcycles contribute to the degradation and pollution of the environment, causing health problems among the general population and among professsional motorcycle taxi drivers in particular. A study conducted on samples of urine and blood collected from motorcycle taxi drivers in Cotonou showed high levels of benzene and ultrafine particles which are likely to damage the deoxyribonucleic acid (DNA) [1-3]. Another 
cross-sectional study conducted among 400 motorcycle taxi drivers, after analysis of the ambient air collected at intersections and motorcycle taxi parks, showed peak concentrations of carbon monoxide of 38.6 ppm (parts per million) in the morning and $78.6 \mathrm{ppm}$ in the afternoon compared to the standard level of $30 \mathrm{ppm}$ with levels of benzene at $7.2 \mu \mathrm{g} / \mathrm{m}^{3}$ [3]. Motorcycle taxi drivers usually work in urban sub-Saharan Africa where the weather is hot with, high ambient temperatures. As a result, pollutants emitted by motors exposed to solar ultraviolet radiation form ozone $\left(\mathrm{O}_{3}\right)$, when a molecule of nitrogen dioxide oxygen is combined with oxygen in the atmosphere $\left(\mathrm{O}_{2}\right)$ to form ozone $\left(\mathrm{O}_{3}\right)$. Ozone, an atmospheric gas, irritates the mucous membranes of the nose, throat, and bronchi may even cause a decrease in lung function. It is therefore likely that drivers who are chronically exposed to ozone and automotive pollutants may, in the medium- or long-term, become victims of respiratory diseases, including bronchospasm, which characterized by paroxysmal respiratory problems and sibilants. Similarly, research carried out in Benin using self-report questionnaires distributed to motorcycle taxi drivers, showed that $23 \%$ of the drivers had difficulty breathing [3]. However, the questionnaire based only on clinical symptoms, seems unreliable to assess bronchospasm. In this sense, the work of Thole [4], Rundell [5] and, more recently Bougault [6] has shown that the existence of clinical symptoms is not necessarily a sign of airway hyperresponsiveness as clinical symptoms do not always coexist with bronchospasm. It therefore seems necessary that the self-report questionnaires distributed to study groups to assess the existence of symptoms of bronchospasm be supplemented by a lung function test. To the best of our knowledge, this approach to diagnosing bronchospasm has not yet been used among the motorcycle taxi drivers population. Therefore, the present work, the first of its kind, conducted in the city of Porto-Novo, Benin, seeks to explore the pulmonary function of motorcycle taxi drivers and the subjects of an equivalent control group for those who experienced: 1) clinical disorders; 2) changes in lung volumes and flow rates; 3 ) prevalence values indicating bronchospasm.

\section{Materials and Methods}

\subsection{Type and Scope of the Study}

This is an analytical and experimental study carried out from 2 to 30 July 2011 on motorcycle taxi drivers residing in the city of Porto-Novo, the political capital city of Benin in West Africa. In this city, intra-urban transport is provided exclusively by motorcycle taxi drivers who carry their clients on the back seats of two-wheeled motorcycles, a type of informal public transport commonly called "Zémidjan". The data on this occupation were obtained from officials of the professional association of motorcycle taxi drivers based in Porto Novo. Car taxis are almost nonexistent in the capital city. Markets, parks, intersections and traffic lights have become major places of concentration for motorcycle taxi drivers.

\subsection{Subject of the Study}

The study sample consists of 48 professional motorcycle taxi drivers and 52 control subjects selected by a simple random probability method. All subjects were male and their mean $( \pm \mathrm{SD})$ age, height, weight and body mass index were respectively $47.02 \pm 8.75 \mathrm{yr}, 170 \pm 0.06 \mathrm{~cm}$, $72.70 \pm 13.30 \mathrm{~kg}$, and $25.34 \pm 3.71 \mathrm{~kg} / \mathrm{m}^{2}$ for professsional motorcycle taxi drivers and were respectively $46.38 \pm 8.81 \mathrm{yr}, 171 \pm 0.06 \mathrm{~cm}, 72.42 \pm 13.01 \mathrm{~kg}$ and $26.81 \pm 3.91 \mathrm{~kg} / \mathrm{m}^{2}$ for control group. A physical examination was used to ensure that each participant was in good health. Subjects are selected among motorcycle taxi drivers who are members of the Association that manages the profession. Subjects in the control group were selected from among those who engage in physical exercise on weekend mornings and who are members of the Association which organizes this activity. Therefore, the experimental group consists of professional motorcycle taxi drivers and the control group is composed of people who occasionally practice sports for health maintenance. The study did not expose individuals to health risk, but in case of discovery of unknown respiratory impairment, the individual was referred to a specialist for consultation and monitoring.

\subsection{Sampling}

The study sample consisted of two subject groups, motorcycle taxi drivers and a control group from the town of Porto-Novo and its surroundings. The work of Fourn and Fayomi that conducted in Cotonou showed clinical signs of asthma in 50 motorcycle taxi drivers [3]. Generally, the size of the study population when it is estimated at less than 10,000 individuals is calculated by the Margaret Formula (1) [7]:

$$
n f=n /[1+n / N]
$$

In this formula, $n$ refers to the size of the study sample and $N$ to the size of the estimated population.

The formula for $n$ is the following (2):

$$
n=\left[Z^{2} \times P \times q\right] / d^{2}
$$

In this formula, $n=$ Number of necessary subjects, $Z=$ Interval of trust at $95 \%(Z=1.96), P=$ the theoretical proportion of groups of people likely to show signs of bronchospasm in a normal population, and $q=1-P$ and refers to the level of trust usually set at $5 \%$. According to the data currently available, the proportion $(P)$ is $15 \%$. Thus, 


$$
n=\left[(1.96)^{2} \times 0.15 \times 0.85\right] /(0.05)^{2}
$$

then,

$$
n f=\{196 /[1+196 / 250]\}
$$

Thus, according to this formula (3), the total sample size should be at least 100 individuals.

\subsection{Selection Criteria}

\subsubsection{Inclusion Criteria}

Individuals meeting the following criteria are included in the study: 1) male; 2) from the Department of Oueme; 3 ) at least 30 years old and a resident of Porto-Novo; 4) provision of the signed informed consent form to participate in the study; 5) own a private motorcycle; 6) holding a membership card of the association of sports practitioners or of motorcycle taxi drivers for at least five years, and 7) having at least five years of experience as motorcycle drivers in Porto-Novo.

\subsubsection{Exclusion Criteria}

Individuals meeting the following criteria are not included in the study 1) being a victim of myocardial infarction during the previous month; 2) having a resting heart rate greater than or equal to $120 \mathrm{bpm}$; 3) being a cigarette smoker 4) suffering from asthma or tuberculosis; 5) having a clinical history of rheumatism or orthopedic symptoms that obstruct the completion of a 6-minute walk test; 6) conducting imperfect maneuvers during respiratory exploration tests; 7) practicing intense sports activities in addition to motorcycle riding, or 8) refusing to sign the informed consent form.

\subsubsection{Materials and Techniques}

Both groups were questioned using a respiratory questionnaire based on that used by the American Thoracic Society (ATS), and also including questions about previously established clinical disorders (e.g., headache and/ or insomnia, conjunctival hyperemia and breathing disorders) [8]. The closed-answer questions most often had dichotomous responses and were translated into the local language goun when necessary. Fact sheets were used to collect information from members of both groups, on age, history of diseases and monthly frequencies of motorcycle taxi use. A SECA brand human weighing machine, accurate to approximately $500 \mathrm{~g}$ with a maximum range of $150 \mathrm{~kg}$, used to determine the body weight of each subject. A wall gauge measuring from zero to two meters was used to measure the height of the subjects standing barefoot and upright, with the head positioned in the horizontal plane of Frankfort [9]. The body mass index $\left(\mathrm{BMI}=\right.$ weight on the square of height $\left.\left(\mathrm{kg} \cdot \mathrm{m}^{-2}\right)\right)$ was calculated. A trail of 30 linear meters delineated by studs placed at each distance of one meter was used to conduct the 6-minute walk tests (6-MWT) as recommended by the ATS [8]. A double decameter calibrated in centimeters with a digital display and a Run Tech measuring tape stopwatch, accurate to one hundredth of a second, were used to measure the length of the track and the duration of walking tests. A Run Tech heart rate monitor model 20,488 was used to record the individuals' heart rates at rest and after physical exercise. Mouthpieces and disposable antibacterial filters (Cosmed Ltd., Rome, Italy) were used to avoid cross contamination between patients. Pulmonary function tests were performed using the Micro quark spirometer (Cosmed Ltd, Rome, Italy). At the beginning of each day of operation, the spirometer is calibrated using a calibration syringe (Cosmed Ltd, Rome, Italy) with a capacity of 3 liters of atmospheric air. In the evaluation of the individuals' pulmonary function, the Micro Spirometer Quark displays the flow volume curve in real-time on the monitor. The flow emitted varies from 0.03 to $20 \mathrm{~L} / \mathrm{s}$ and with maximum volume of $10 \mathrm{~L}$, with an accuracy of plus or minus 3\%, as recommended by the European Respiratory Society [10] and the American Thoracic Society [8]. The Micro Quark equipped with a turbine vane sensor works as follows: a light is flashed and is continuously recorded by a photoelectric cell. The rotating impeller with vanes blocks the light path and changes the electrical collection, depending on the speed of movements induced by the volume of air exhaled by the individual. The interruption of the beam depends on the speed of the air passing through the initial deflector. The electrical impulses are recorded by a tachometer.

\subsubsection{Experimental Protocol}

\subsubsection{Experimentation Plan}

In the first phase of experimentation, the motorcycle taxi drivers and the selected members of the control group filled out the individual information sheets and informed consent forms. The BMI and height of the individuals were measured. In the second phase, the subject, sitting in a chair, observes 15 minutes of passive rest after which the following measurements are taken: heart rate while sitting, lung volumes and flow rates while standing. After a 10 minutes passive break, the subject performs the first 6-minute walk test (6-MWT1) followed by 10 minutes of rest, then a second walk test (6-MWT2). At the end of the 6-MWT2, the heart rate is immediately measured while the measurement of respiratory variables is performed after a 10-minute break.

\subsubsection{Pulmonary Function Tests}

The pulmonary function tests (PFT) were performed under the supervision of a medical technician. After determining the size, body weight, age, sex and race of the individual, the spirometer unit automatically calculates the 
theoretical values of each respiratory parameter. In the PFT, the individual, while standing with nose pinched and a turbine between their two hands breathed naturally and quietly through the mouthpiece connected to the spirometer. The individual was then instructed to inflate his lungs, and then breathe the air as quickly as possible, in a continuous and complete way. After the test, the best test was selected among the three reproducible tests that have been validated according to the algorithms of the spirometer. The lung volumes and peak flows were recorded.

\subsubsection{Six-Minute Walk Test (6-MWT)}

This test was carried out according to the protocol suggested by the ATS [8]. Subjects are asked to keep a running speed as regular as possible and travel the greatest distance possible in six minutes, running back and forth between two 30-meter markers. All individuals performed the 6-MWT without encouragement and under the supervision of three sports instructors. Because of possible influences that may induce biorhythms that impact performance, all six-minute walk tests were conducted in the morning between 7:30 and 9:30 am, and food intake was not allowed before or during that time-frame. The Intensive Care Unit of Porto Novo Central Hospital was informed of the experiment to prepare for any eventuality. This study was approved by the Scientific Committee of Science and the Technology Sector of the Sports and Physical Activities Department (CSS/sport science), AbomeyCalavi University, in accordance with the Helsinki Act of 1975 on ethics.

\subsubsection{Variables Studied}

2.4.5.1. Variables Measured at Rest before the 6-MWT The forced vital capacity (FVC), the forced expiratory volume in one second (FEV1), the peak expiratory flow (PEF), the forced expiratory flow from $25 \%-75 \%$ of the vital capacity $\left(\mathrm{FEF}_{25-75}\right)$, the forced expiratory flow from $50 \%$ of the vital capacity $\left(\mathrm{FEF}_{50}\right)$ and the forced expiratory flow from $25 \%$ of the vital capacity $\left(\mathrm{FEF}_{25}\right)$ obtained from respiratory exploration are used as respiratory variables. The theoretical maximum heart rate (predicted $H R_{\max }$ ) equal to the individual's age subtracted from 220 (220-age), was observed while all subjects were at rest. These variables, noted for both groups of individuals prior to completion of 6-MWT1, were considered to be resting values. Comparison of respiratory variables of the group of motorcycle taxi drivers with those of the control group was used to assess the risk from inhalation of exhaust gases from vehicles.

\subsubsection{Variables Measured after the 6-MWT}

The maximum heart rates $\left(\mathrm{HR}_{\max }\right)$ noted at the end of 6-MWT were expressed as percentage change compared to the predicted $\mathrm{HR}_{\max }$, as assessed at the end of the ex- periment, in addition to the level of intensity of the exercise test reached by the subjects.

These parameters were calculated using the following formula.

$$
\mathrm{HR}_{\max }(\%)=\mathrm{HR}_{\max } \times 100 / \text { Predicted } \mathrm{HR}_{\text {max }}
$$

The best variables recorded at the end of 6-MWT were considered post-exercise values. At the end of 6-MWT, the six-minute walking distance (6-MWD) was calculated following formula.

$$
\begin{aligned}
& 6-\mathrm{MWD}(\mathrm{m}) \\
& =\{(\text { Number of round trips } \times 60 \mathrm{~m})+\text { final meters }\}
\end{aligned}
$$

At the end of 6-MWT, the comparison of respiratory variables in the experimental group with the control group was used to evaluate the variation of these parameters. The diagnosis of bronchospasm was said to be positive in a subject if his post-FEV dropped at least $10 \%$ compared with the value at rest as calculated using the formula.

$$
\begin{aligned}
& \Delta \mathrm{FEV}(\%) \\
& =\{(\mathrm{FEV} \text { post exercise } \times 100) / \mathrm{FEV} \text { pre exercise }\}-100
\end{aligned}
$$

\subsubsection{Statistical Analysis}

The variables were processed using StatView 5 software (version 5) (Abacus Concepts Inc. Berkeley, CA, USA). Descriptive statistics were generated for each variable. The normal distribution of variables, as well as the equivalence of their respective variances, was checked by the Kolmogorov-Smirnov test and the F-test. Comparisons between groups were performed by unpaired t-tests after the normality of the distribution and homogeneity of variances were verified. For all statistical analyses, the null hypothesis was rejected at a probability of $P<0.05$.

\section{Results}

Table 1 shows the comparison of biometric parameters and distances between motorcycle taxi drivers and members of control group. The differences were not significant $(p>0.05)$. In contrast, the percentage of predicted $\mathrm{HR}_{\max }$ of motorcycle taxi drivers was significantly $(p<$ 0.001) lower than the control group (Table 1). Symptoms recorded during the self-reported questionnaires among motorcycle taxis drivers, were related to clinical disorders (headache and/or insomnia) in 30\% of cases, conjunctival hyperemia $(25 \%)$, digestive disorders such as nausea and vomiting (26\%), and respiratory disorders and persistent bronchorrhea (20\%). In the control group, the same disorders were noted with lower frequencies: headache $(18.5 \%)$, conjunctival hyperemia $(13 \%)$, and headache $(16 \%)$. The included motorcycle drivers had a total riding time of 8 hours minimum and 12 hours maxi- 
Table 1. Comparisons of biometric, distances traveled and heart rates between motorcycle taxi drivers group and control group.

\begin{tabular}{ccc}
\hline Parameters & $\begin{array}{c}\text { Motorcycle taxi } \\
\text { drivers Group }(n=48)\end{array}$ & Control Group $(n=52)$ \\
\hline & Mean $\pm \mathrm{SD}$ & Mean \pm SD \\
Age (years) & $47.02 \pm 8.75$ & $46.38 \pm 8.81$ \\
Height (m) & $1.70 \pm 0.06$ & $1.71 \pm 0.06$ \\
Weight (kg) & $72.70 \pm 13.30$ & $72.42 \pm 13.01$ \\
BMI $\left(\mathrm{kg} \cdot \mathrm{m}^{-2}\right)$ & $25.34 \pm 3.71$ & $26.81 \pm 3.91$ \\
6-MWD (m) & $615.63 \pm 65.15$ & $637.05 \pm 79.88$ \\
$\mathrm{HR}_{\max }(\%)$ Pred & $52.36 \pm 9.80^{* * *}$ & $66.00 \pm 9.58$ \\
\hline
\end{tabular}

SD: Standard deviation; $\mathrm{HR}_{\max }$ : Heart Rate max; Pred: Predicted; 6-MWD: 6-Minute Walking Distance; BMI: Body Mass Index; ${ }^{* * *} p<0.001$

mum per day whereas the control subjects were exposed to pollution in traffic for one to two hours per day.

Among motorcycle taxi drivers, Table 2 shows that, at rest and before physical exercise, respiratory variables were significantly $(p<0.01)$ lower than those of the control group.

The same results were noted after the physical exercise of 6MWT (Table 3). A drop of at least 10\% in FEV post exercise was observed in 15 motorcycle taxi drivers out of a total of 48, with an average drop in FEV by $19.17 \%$ $(10.04 \% 37.04 \%)$, which is a prevalence of bronchospasm of $31.07 \%$. In the control group, this criterion was found in 12 subjects out of a total of 52, with an average drop of $17.36 \%$ in FEV (10.08\% $37.41 \%)$, which is a prevalence of $23.07 \%$.

\section{Discussion}

The aim of this study was to test lung function and to determine the prevalence of bronchospasm among motorcycle taxi drivers working in urban areas of PortoNovo. Cross-sectional studies previously conducted in Benin showed that in urban environments where informal public transport activities are carried out, the environment is highly polluted [1-3]. Indeed, urban pollution is the result of pollutants emissions from various sources, including traffic and industrial activities within cities. The most prevalent pollutants generated from road transport are nitrogen oxides $\left(\mathrm{NO}\right.$ and $\left.\mathrm{NO}_{2}\right)$, carbon monoxide (CO), sulfur dioxide $\left(\mathrm{SO}_{2}\right)$, volatile organic compounds and particulate matter [11]. In addition, ozone is a common pollutant formed by a photochemical reaction, resulting from the sufficient duration of sunlight in Porto-Novo at high ambient temperatures. Similarly, some particles are emitted directly or formed by reaction between gases and particles. The analysis of ambient air in these cities of Benin reveals a concentration of carbon monoxide rang-
Table 2. Comparisons of respiratory variables between Motorcycle taxi drivers group and Control group before 6-MWT.

\begin{tabular}{ccc}
\hline $\begin{array}{c}\text { Respiratory } \\
\text { variables }\end{array}$ & $\begin{array}{c}\text { Motorcycle taxi } \\
\text { drivers Group }(\mathrm{n}=48)\end{array}$ & Control Group $(\mathrm{n}=52)$ \\
\hline Mean $\pm \mathrm{SD}$ & Mean $\pm \mathrm{SD}$ \\
$\mathrm{FVC}(\mathrm{L})$ & $2.97 \pm 0.68^{* *}$ & $3.43 \pm 0.67$ \\
$\mathrm{FEV} 1(\mathrm{~L})$ & $2.00 \pm 0.55^{* *}$ & $2.42 \pm 0.49$ \\
$\mathrm{PEF}\left(\mathrm{L} \cdot \mathrm{s}^{-1}\right)$ & $2.82 \pm 1.04^{* *}$ & $3.84 \pm 1.47$ \\
$\mathrm{FEF}_{25-75}\left(\mathrm{~L} \cdot \mathrm{s}^{-1}\right)$ & $1.76 \pm 0.62^{* * *}$ & $2.33 \pm 0.66$ \\
$\mathrm{FEF}_{50}\left(\mathrm{~L} \cdot \mathrm{s}^{-1}\right)$ & $2.06 \pm 0.73^{* *}$ & $2.69 \pm 0.87$ \\
$\mathrm{FEF}_{25}\left(\mathrm{~L} \cdot \mathrm{s}^{-1}\right)$ & $1.02 \pm 0.39^{* *}$ & $1.35 \pm 0.45$ \\
\hline
\end{tabular}

SD: Standard deviation; FVC: forced vital capacity; FEV1: forced expiratory volume in one second; PEF: peak expiratory flow; $\mathrm{FEF}_{25-75}$ : expiratory flow from $25 \%-75 \%$ of the vital capacity; $\mathrm{FEF}_{25}, \mathrm{FEF}_{50}$ : instantaneous expiratory flows at $25 \%$ and $50 \%$ respectively; ${ }^{* *} p<0.01 ;{ }^{* * *} p<0.001$.

Table 3. Comparisons of respiratory variables between Motorcycle taxi drivers group and Control group after 6MWT.

\begin{tabular}{ccc}
\hline $\begin{array}{c}\text { Respiratory } \\
\text { variables }\end{array}$ & $\begin{array}{c}\text { Motorcycle taxi } \\
\text { drivers Group }(n=48)\end{array}$ & $\begin{array}{c}\text { Control Group } \\
(n=52)\end{array}$ \\
\hline Mean $\pm \mathrm{SD}$ & Mean $\pm \mathrm{SD}$ \\
FEC (L) & $3.06 \pm 0.70^{* *}$ & $3.45 \pm 0.66$ \\
$\mathrm{PEF}\left(\mathrm{L} \cdot \mathrm{s}^{-1}\right)$ & $1.95 \pm 0.54^{* * *}$ & $2.46 \pm 0.48$ \\
$\mathrm{FEF}_{25-75}\left(\mathrm{~L} \cdot \mathrm{s}^{-1}\right)$ & $1.71 \pm 0.60^{* * *}$ & $3.89 \pm 1.63$ \\
$\mathrm{FEF}_{50}\left(\mathrm{~L} \cdot \mathrm{s}^{-1}\right)$ & $2.03 \pm 0.72^{* *}$ & $2.28 \pm 0.72$ \\
$\mathrm{FEF}_{25}\left(\mathrm{~L} \cdot \mathrm{s}^{-1}\right)$ & $0.98 \pm 0.40^{* *}$ & $2.61 \pm 1.01$ \\
\hline
\end{tabular}

SD: Standard deviation; FVC: forced vital capacity; FEV1: forced expiratory volume in one second; PEF: peak expiratory flow; $\mathrm{FEF}_{25-75}$ : expiratory flow from $25 \%-75 \%$ of the vital capacity; $\mathrm{FEF}_{25}, \mathrm{FEF}_{50}$ : instantaneous expiratory flows at $25 \%$ and $50 \%$ respectively; ${ }^{* *} p<0.01 ;{ }^{* * *} p<0.001$.

ing between 26 to $38.6 \mathrm{ppm}$ in the morning and 58 to 78.6 $\mathrm{ppm}$ in the afternoon against a $30 \mathrm{ppm}$ [3]. Likewise, benzene was identified with an average value of $7.2 \mu \mathrm{g} / \mathrm{m}^{3}$. On the basis of a self-report questionnaire that reveals respiratory disorders in the motorcycle taxi drivers, this study suggest that this bronchopulmonary infection could be caused by automobile pollution. To assess possible influences of the ambient polluted air on the lung function of motorcycle taxi drivers and control group residing in Porto-Novo, respiratory variables were carefully measured in the resting state during pulmonary function testing. In addition, the individuals were subjected to a stress test because the bronchospasm is recognized as being a latent respiratory disease. The physical characteristics of individuals such as height, body mass and age, that may affect the respiratory variables were compared between 
the group of motorcycle taxi drivers and the control group. These comparisons showed no significant difference between the two groups $(p>0.05)$, thereby ensuring their comparability for the purposes of this study. Variables observed in motorcycle taxi drivers were assessed with reference to the control group. The main results noted in this study were as follows: 1) the frequencies of symptoms observed among motorcycle taxi drivers are higher than those recorded in the control group; 2) the motorcycle taxi drivers experienced, at rest and after exercise testing, peak flow volumes and lung capacity that were significantly lower $(p<0.01)$ than in the individuals of the control group and; 3 ) the group of motorcycle taxi drivers presented a prevalence of $31.25 \%$ of bronchospasm, which exceeds the $8.18 \%$ prevalence presented in the control group. However, proportions in the control group did not differ significantly $(p>0.05)$. The high frequency of symptoms, respiratory depression variables and high values of prevalence of bronchospasm observed in motorcycle taxi drivers compared to the control group may be due to exhaust gas poisoning. Indeed, inhalation of oxidants such as $\mathrm{NO}_{2}$ generated by road traffic can degrade cell membranes constituents through the toxic peroxides [12]. Experimental studies conducted on animals show a reactivity of $\mathrm{NO}_{2}$ with the airway epithelium and thickening of small airways, accompanied by a proliferation of connective tissue around the bronchus [13]. Another study on rats showed a decrease in to the cilia of respiratory epithelia that play an essential role in removing particles reaching the bronchi and bronchioles [14]. Moreover, the toxic effects induced by $\mathrm{NO}_{2}$ generally observed on the respiratory mucosa, may range from irritation to asthma attacks, following a bronchial reactivity with cough [15]. An irritating effect on the ocular membranes mucous (conjunctiva) and a decreased resistance to pathogens were also noted [16]. $\mathrm{SO}_{2}$, a very soluble irritant, also acts synergistically with other substances, including particulate matter. The $\mathrm{SO}_{2}$ inhaled is retained by the watery surfaces of the nose and upper respiratory tract thereby causing eye irritation, skin and respiratory infection. Exposure to $\mathrm{SO}_{2}$ increases the incidence of chronic bronchitis and pharyngitis. Indeed, epidemiological studies show that exposure to sulfur dioxide $\left(\mathrm{SO}_{2}\right)$ at a concentration of approximately $1000 \mu \mathrm{g} / \mathrm{m}^{3}$ may cause or exacerbate latent respiratory infections and result in increased mortality caused by respiratory or cardiovascular disease [17]. Similarly, the work of BruskeHohlfeld [18] showed that an increased level of air pollution consisting of fine particles, especially from vehicle emissions, may lead to respiratory problems. In addition, the high production of particles, carbon monoxide (CO), lies in the anoxia-induced conversion of hemoglobin to car- boxyhemoglobin while that of nitrogen dioxide $\left(\mathrm{NO}_{2}\right)$ and suspended ultrafine particles are involved in airway dysfunction [19-21]. From the measurement of lung function performed on children living in Los Angeles [22] and China [23], the effect of ozone on respiratory variables has been highlighted. Indeed, some respiratory parameters such as FEV1, $\mathrm{FEF}_{25-75}$ and FVC were observed to decrease over a period of monitoring from 1984 to 1987 [22]. Our results confirm those of Cakmak [24], which conclude that chronic exposure to high concentrations of polluted air causes a reduction in lung function. Under these conditions, how can we explain differences in the frequency of symptoms, respiratory variables and values of bronchospasm prevalence noted among motorcycle taxi drivers and the control group? As part of their profession, the motorcycle taxi drivers are exposed daily to automotive pollutants for 8 hours minimum and sometimes as many as 10 to 12 hours, compared with control subjects who are exposed to automotive pollutants one to two hours per day because of their daily activities. Because individuals in both groups were not subjected to the same level and duration of exposure to automotive pollutants, it can be assumed that this fact can explain the differences noted in frequency of symptoms, as well as differences in recorded ventilatory parameters observed at rest. Indeed, motorcycle taxi drivers at rest showed a significant reduction in lung function compared with the control group (Table 2). The diagnosis of lung function sometimes requires the use of exercise testing which may reveal latent or overt bronchospasm. Indeed, during physical exercise, the airways are exposed to progressively hyper osmolarity. This dehydrating mechanism leads to an increase in the concentrations of $\mathrm{Ca}^{2+}, \mathrm{K}^{+}, \mathrm{Cl}^{-}$and $\mathrm{Na}^{+}$. As a result, the inflammatory mediators are released and induce airway contraction $[25,26]$. As part of the study and after the 6-minute walk test, motorcycle taxi drivers showed respiratory variables significantly lower than those noted in individuals of the control group (Table 3). Can physical exercise, with its implications in the occurrence of bronchospasm, explain the observed differences in respiratory variables? The change in respiratory parameters noted at the end of the 6-minute walk test has several explanations. In fact, the 6-minute walk test is a sub maximal exercise, classically tailored to elderly patients, as recommended by the ATS [8]. The heart rates observed after the exercise test confirm that the 6-minute walk test is actually sub maximal because they correspond to $52.36 \%$ and $66 \%$ of predicted $\mathrm{HR}_{\max }$ in motorcycle taxi drivers and the control group respectively. In addition, variables observed at rest and after physical exercise did not differ significantly between the two groups. Motorcycle taxi drivers seem to be more physically fit and able than the control group because at the end of the effort, the average $\mathrm{HR}_{\max }$ recorded among motorcycle taxi drivers $(52.36 \pm 9.80 \%)$ is significantly $(p<0.01)$ lower than that of control subjects $(66 \% \pm$ 
9.58\%). The fact remains, however, that the comparison of the distances traveled by the two groups was not significantly different $(p>0.05)$ (Table 1). Furthermore, the fact that motorcycle taxis drivers ventilate polluted air for many hours and the corresponding risk of contact between the bronchial mucosa and allergens in the air could increase their sensitivity $[27,28]$. Indeed, in the event of a hypersensitivity to these allergens, the IgE-dependent mechanism would become active, stimulate mast cell membrane and facilitate the penetration of calcium into the cell nucleus. Under these conditions, the mast cells would degranulate the inflammatory mediators which may also induce contraction of smooth muscles of the airways. The findings of previous studies, in the studies $[29,30]$ also point to a link between exposure to gases emitted by traffic and respiratory infection, including bronchospasm. Therefore, the quality of ambient air inhaled at rest as well as during physical exercise appears to be a key factor that can lead to bronchospasm, the prevalence of which can be determined from comparing FEV at rest and after exerting effort. The prevalence of bronchospasm observed in the control group $(23.07 \%)$ is higher than that reported in the general population which ranges from $4 \%$ to $20 \%$ [31-33]. In addition, at the end of the 6-MWT, the prevalence of bronchospasm among motorcycle taxi drivers $(31.25 \%)$ is higher than that observed among basketball players in Benin (26\%) [34]. Chronic exposure of the general population and of the motorcycle taxi drivers to traffic pollution has emerged as a public health problem whose consequences still raise health concerns. Thus, studies showing links between exposure to pollution from nearby urban areas and respiratory diseases are not unanimous in their findings. Therefore, the knowledge of environmental conditions and their impact on human health require an interdisciplinary approach.

\section{Conclusion}

Cross-sectional studies previously conducted in Benin on motorcycle taxi drivers have shown high levels of auto pollutants. These pollutants consist of nitrogen oxides ( $\mathrm{NO}$ and $\mathrm{NO}_{2}$ ), carbon monoxide, benzene and volatile organic compounds that influence the well-being and, respiratory health of individuals. For this reason, the present study investigated the lung function of motorcycle taxi drivers, individuals with high exposure to automotive pollutants to diagnose overt or latent respiratory infection. The results of the study show that motorcycle taxi drivers, both at rest and after exercise, experience high frequencies of asthma symptoms, significant reductions in lung volumes and flow rates and high prevalence of bronchospasm. These results clearly show the existence of respiratory disorders due to chronic exposure to automotive pollutants. The results should enable city counselors of Porto-Novo, to better understand the respi- ratory hazards that motorcycle taxi drivers face every day. To mitigate the harmful effects of pollutants, gasoline vehicles that do not have catalytic converters and diesel cars without particulate filters should be banned. Finally, the study raises awareness about the exposure risks and suggests preventive measures to preserve the health of motorcycle taxi drivers. Measures including, regular inspections of imported used vehicles, the reduction of exhaust gas, the strengthening of the law on atmospheric environment protection and proper management of crossroads, can reduce the production of automotive pollutants in the city of Porto-Novo, Benin.

\section{Acknowledgements}

The authors would like to thank professional motorcycle taxi drivers and subjects in the control group for their participation in the study and field and laboratory staff that collected the data.

\section{REFERENCES}

[1] P. H. Avogbe, L. Ayi-Fanou, H. Autrup, et al., "Ultrafine Particulate Matter and High-Level Benzene Urban Air Pollution in Relation to Oxidative DNA Damage," Carcinogenesis, Vol. 26, No. 3, 2005, pp. 613-620. doi:10.1093/carcin/bgh353

[2] L. Ayi-Fanou, P. H. Avogbe, B. Fayomi, et al., "DNAAdducts in Subjects Exposed to Urban Air Pollution by Benzene and Polycyclic Aromatic Hydrocarbons (PAHs) in Cotonou, Benin," Environmental Toxicology, Vol. 26, No. 1, 2011, pp. 93-102. doi:10.1002/tox.20533

[3] L. Fourn and E. B. Fayomi, "Air Pollution in Urban Area in Cotonou and Lokossa, Benin," Bulletin de la Société de Pathologie Exotique, Vol. 99, No. 4, 2006, pp. 264-268.

[4] R. T. Thole, R. E. Sallis, A. L. Rubin, et al., "ExerciseInduced Bronchospasm Prevalence in Collegiate CrossCountry Runners," Medicine and Science in Sports and Exercise, Vol. 33, No. 10, 2001, pp. 1641-1646. doi:10.1097/00005768-200110000-00005

[5] K. W. Rundell, J. Im, L. B. Mayers, et al., "Self-Reported Symptoms and Exercise-Induced Asthma in the Elite Athlete," Medicine and Science in Sports and Exercise, Vol. 33, No. 2, 2001, pp. 208-213. doi:10.1097/00005768-200102000-00006

[6] V. Bougault, J. Turmel and L. P. Boulet, "Bronchial Challenges and Respiratory Symptoms in Elite Swimmers and Winter Sport Athletes: Airway Hyperresponsiveness in Asthma: Its Measurement and Clinical Significance," Chest, Vol. 138, No. 2, 2010, pp. 31S-37S. doi:10.1378/chest.09-1689

[7] O. A. Margaret, "Research Methodology with Statistics for Health and Social Sciences," Nathadex Publishers, Ilorin, 2003.

[8] American Thoracic Society, "Standardization of Spirometry: 1994 Update," American Journal Respiratory Critical Care and Medicine, Vol.152, No. 3, 1995, pp. 11071136. 
[9] T. G. Lohman, A. F. Roche and R. Martorell, "Anthropometric Standardization Reference Manual," Human Kinetics Books, Champaign, 1998.

[10] European Respiratory Society, "Standardized Lung Function Testing. Official Statement of the European Respiratory Society," European Respiratory Journal, Vol. 6, 1993, pp. 53-83.

[11] S. Hankey, J. D. Marshall and M. Brauer, "Health Impacts of the Built Environment: Within-Urban Variability in Physical Inactivity, Air Pollution and Ischemic Heart Disease Mortality," Environmental Health Perspectives, Vol. 120, No. 2, 2012, pp. 247-253. doi: $10.1289 /$ ehp. 1103806

[12] J. D. Crapo, B. E. Barry, L. Y. Chang, et al., "Alterations in Lung Structure Caused by Inhalation of Oxidants," Journal of Toxicology and Environmental Health, Vol. 13, No. 2-3, 1984, pp. 301-321. doi:10.1080/15287398409530500

[13] L. E. Fujinaka, D. M. Hyde, C. G. Plopper, et al., "Respiratory Bronchiolitis Following Long-Term Ozone Exposure in Bonnet Monkeys: A Morphometric Study," Experimental Lung Research, Vol. 8, No. 2-3, 1985, pp. 167-190. doi:10.3109/01902148509057520

[14] B. E. Barry, R. R. Mercer, F. J. Miller, et al., "Effects of Inhalation of 0.25 ppm Ozone on the Terminal Bronchioles of Juvenile and Adult Rats," Experimental Lung Research, Vol. 14, No. 2, 1988, pp. 225-245. doi:10.3109/01902148809115126

[15] C. Pénard-Morand, C. Raherison, D. Charpin, et al., "Long-Term Exposure to Close-Proximity Air Pollution and Asthma and Allergies in Urban Children," European Respiratory Journal, Vol. 36, No. 1, 2010, pp. 33-40. doi:10.1183/09031936.00116109

[16] B. Rijcken, J. P. Schouten, X. Xu, et al., “Airway Hyperresponsiveness to Histamine Associated with Accelerated Decline in FEV1," American Journal of Respiratory and Critical Care Medicine, Vol. 151, No. 5, 1995, pp. 13771382.

[17] M. C. White, R. A. Etzel, W. D. Wilcox, et al., "Exacerbations of Childhood Asthma and Ozone Pollution in Atlanta," Environmental Research, Vol. 65, No. 1, 1994, pp. 56-68. doi:10.1006/enrs.1994.1021

[18] I. Brüske-Hohlfeld, A. Peters and H. E. Wichmann, "Do Nanoparticles Interfere with Human Health?" Ecological Perspectives for Science and Society, Vol. 14, No. 1, 2005, pp. 21-23.

[19] M. Brauer, K. Lee, J. D. Spengler, et al., "Nitrogen Dioxide in Indoor Ice Skating Facilities: An International Survey," Journal of the Air \& Waste Management Association, Vol. 47, No. 10, 1997, pp. 1095-1102. doi:10.1080/10473289.1997.10464399

[20] J. I. Levy, K. Lee, Y. Yanagisawa, et al., "Determinants of Nitrogen Dioxide Concentrations in Indoor Ice Skating Rinks," American Journal of Public Health, Vol. 88, No. 12, 1998, pp. 1781-1786. doi:10.2105/AJPH.88.12.1781

[21] K. W. Rundell, "High Levels of Airborne Ultrafine and Fine Particulate Matter in Indoor Ice Arenas," Inhalation Toxicology, Vol. 15, No. 3, 2003, pp. 237-250. doi: $10.1080 / 08958370304502$
[22] K. H. Kilburn, R. H. Warshaw and J. C. Thornton, "Expiratory Flows Decreased in Los Angeles Children from 1984 to 1987: Is this Evidence of Effects of Air Pollution?" Environmental Research, Vol. 59, No. 1, 1992, pp. 150-158. doi:10.1016/S0013-9351(05)80235-X

[23] L. Liu and J. Zhang, "Ambient Air Pollution and Children's Lung Function in China" Environment International, Vol. 35, No. 1, 2009, pp. 178-186. doi:10.1016/j.envint.2008.06.004

[24] S. Cakmak, R. Dales, J. Leech, et al., "The Influence of Air Pollution on Cardiovascular and Pulmonary Function and Exercise Capacity: Canadian Health Measures Survey (CHMS)" Environmental Research, Vol. 111, No. 8, 2011, pp. 1309-1312. doi:10.1016/j.envres.2011.09.016

[25] S. D. Anderson and P. Kippelen, "Airway Injury as a Mechanism for Exercise-Induced Bronchoconstriction in Elite Athletes," Journal of Allergy and Clinical Immunology, Vol. 122, No. 2, 2008, pp. 225-235. doi:10.1016/j.jaci.2008.05.001

[26] S. D. Anderson and K. Holzer, "Exercise-Induced Asthma: Is It the Right Diagnosis in Elite Athletes?" Journal of Allergy and Clinical Immunology, Vol. 106, No. 3, 2000, pp. 419-428. doi:10.1067/mai.2000.108914

[27] M. W. Frampton, "Does Inhalation of Ultrafine Particles Cause Pulmonary Vascular Effects in Humans?" Inhalation Toxicology, Vol. 19, No. S1, 2007, pp. 75-79. doi:10.1080/08958370701495071

[28] C. C. Daigle, D. C. Chalupa, F. R. Gibb, et al., "Ultrafine Particle Deposition in Humans during Rest and Exercise," Inhalation Toxicology, Vol. 15, No. 6, 2003, pp. 539-552. doi: $10.1080 / 08958370304468$

[29] H. R. Anderson, R. Ruggles, K. D. Pandey, et al., “Ambient Particulate Pollution and the World-Wide Prevalence of Asthma, Rhino Conjunctivitis and Eczema in Children," Occupational and Environmental Medicine, Vol. 67, No. 5, 2010, pp. 293-300. doi:10.1136/oem.2009.048785

[30] B. Brunekreef, A. W. Stewart, H. R. Anderson, et al., "Self-Reported Truck Traffic on the Street of Residence and Symptoms of Asthma and Allergic Disease," Environmental Health Perspectives, Vol. 117, No. 11, 2009, pp. 1791-1798. doi:10.1289/ehp.0800467

[31] K. W. Rundell and D. M. Jenkinson, "Exercise-Induced Bronchospasm in the Elite Athletes," Sports Medicine, Vol. 32, No. 9, 2002, pp. 583-600. doi:10.2165/00007256-200232090-00004

[32] W. Nystad, J. Harris and J. S. Borgen, "Asthma and Wheezing among Norwegian Elite Athletes," Medicine and Science in Sports and Exercise, Vol. 32, No. 2, 2000, pp. 266-270. doi:10.1097/00005768-200002000-00003

[33] I. Helenius, H. O. Tikkanen and T. Haahtela, "Association between Type of Training and Risk of Asthma in Elite Athletes," Thorax, Vol. 52, No. 2, 1997, pp.157-160. doi:10.1136/thx.52.2.157

[34] F. Messan, M. M. Lawani, T. Marqueste et al., "Evaluation du $\mathrm{DEM}_{25}$ chez 156 Enfants Exposés à la Pollution Automobile dans la Municipalité de Cotonou,"Mali Medical, Vol. 4, 2011, pp.16-21. 